Article

\title{
Experimental Comparative Study of Dynamic Behavior in Solution Phase of $C$-Tetra(phenyl)resorcin[4]arene and $C$-Tetra(phenyl)pyrogallol[4]arene
}

\author{
José Luis Casas-Hinestroza, Miguel Ángel Vela Suazo and Mauricio Maldonado Villamil * \\ Departamento de Química, Facultad de Ciencias, Universidad Nacional de Colombia-sede Bogotá, \\ Carrera 30 \# 45-03, Bogotá 111321, Colombia; jlcasash@unal.edu.co (J.L.C.-H.); mvela@unal.edu.co (M.Á.V.S.) \\ * Correspondence: mmaldonadov@unal.edu.co; Tel./Fax: +57-1-316-5000
}

Received: 11 March 2020; Accepted: 8 May 2020; Published: 12 May 2020

\begin{abstract}
The synthesis of phenyl-resorcinarenes and pyrogallolarenes is known to produce a conformational mixture of cone and chair isomers. Depending on the synthesis conditions the composition of the conformational mixture is variable; however, the cone conformer is the greatest proportion of phenyl-resorcin[4]arenes and chair conformer of pyrogallol[4]arenes. The experimental evidence suggests that phenyl-substituted resorcinarene and pyrogallolarene exist as a dynamic boat in solution.
\end{abstract}

Keywords: polyhydroxylated platform; conformational behavior; conformers; dynamic studies; dynamic boat

\section{Introduction}

Among the macromolecules there are specific groups with chemical and structural characteristics that have attracted attention in recent years in different fields of research. An interesting example is the Calixarenes family—in particular resorcinarenes and pyrogallolarenes [1] — which can be obtained by reactions between aldehydes and resorcinol or pyrogallol, respectively, the latter being the main difference between the two types of macrocycles (Scheme 1). Using different phenols for the synthesis leads to different properties; for example, resorcinarenes have two active sites on the upper rim (position 2 and hydroxyl groups), where the macromolecule can be functionalized or derivatized. A different case occurs with pyrogallolarenes, which only have hydroxyl groups on the upper rim, which restricts their derivation possibilities somewhat as compared with resorcinarenes. In both cases, the cyclocondensation reaction is performed under acid catalysis conditions [2-4], which has the advantage of a low cost together with a minimum of synthetic steps, in addition to a minimum variation in the synthetic design of the macrocyclic molecules with different chemical functions [5]. 


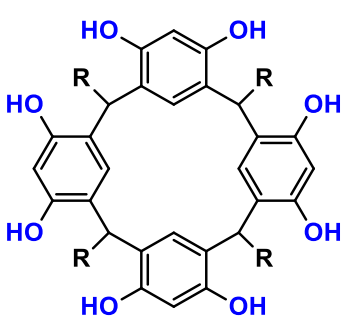

Resorcin[4]arene

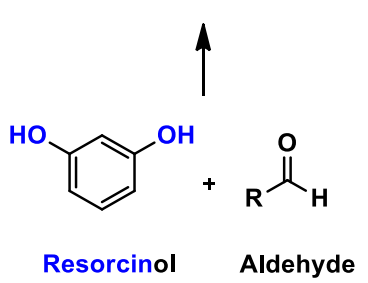

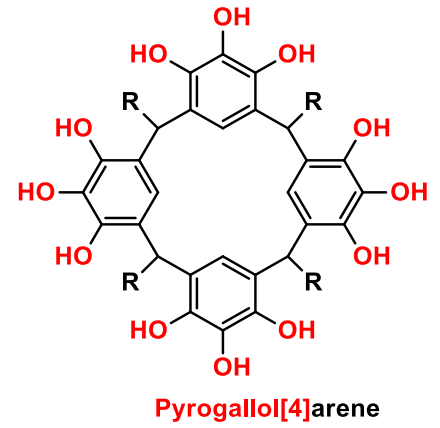

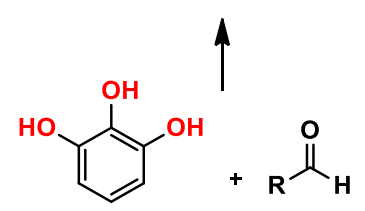

Pyrogallol Aldehyde

Scheme 1. Synthesis of resorcinarenes and pyrogallolarenes.

An interesting aspect of this type of compound is that it can adopt different structural isomers. This often depends on the reaction conditions or the type of aldehyde used and the reaction time [6]. Among the most prominent isomers are those of the cone and boat type, thanks to the fact that they are more stable and are usually obtained in greater proportion when the synthesis is carried out $[7,8]$. The influence of the substituent on the lower rim can influence the type of conformation that can be obtained. In this way, resorcinarenes with aliphatic substitutions on the lower rim exhibit the same cone-type isomers as the majority, while the resorcinarenes that have aromatic substitutions show cone-chair-type isomeric mixtures, in which their relationship varies depending on the synthesis conditions [9]. With respect to pyrogallolarenes, the products obtained in the synthesis with aliphatic aldehydes show a tendency for the formation of cone isomers in greater proportion. On the other hand, those synthesized from aromatic aldehydes show a preference for producing chair-type isomers $[10,11]$. Even so, as with resorcinarenes, there are some cases where the tendency changes or an isomeric mixture is produced, depending on the synthesis conditions [12].

The cone and boat isomers have structural properties that have been beneficial in the vast majority of applications, due to the fact that these forms have an electron-rich cavity [13], which can interact with other molecules or analytes in such a way that they can stay within these macrocycles. Another important feature is that their hydroxyl groups, both in resorcinarenes and pyrogallolarenes, have an upward orientation, which sometimes can form supramolecular assemblies through hydrogen bonds, such as capsules or aggregates. These bonds commonly established between the upper edges of resorcinarenes or pyrogallolarenes are not unique forms such as supramolecular structures-there are also assemblies where agents such as solvents [14], coordinating metals [15,16] and covalent bonds $[17,18]$ exist. There are several applications where resorcinarenes and pyrogallolarenes have contributed to significant advances, basically due to their versatility, both in synthesis and derivatives and in their molecular structure itself. A field where they have been widely used is host-guest systems [19-21], since the electron-rich cavity of cone-type isomers allows different types of interactions with molecules [22] to be established, especially with tetraalkylammonium-type salts or metal cations [23,24]. This has led to different areas of applications, such as sensors [25], catalysis [26,27], heavy metal complexes for purification of water tributaries [28-30] and chemical separations by modification of Hight Performance Liquid Chromatography (HPLC) columns [31-34], among others.

The aforementioned applications are possible because the polyhydroxylated platforms undergo conformations and conformational interconversions in solution [35], which allows host-guest interactions. For example, the conformation of resorcinarenes can be rigidified into a cone by linking the hydroxyl groups of the upper rim, which provides a higher degree of preorganization. 
Nevertheless, in solution the rccc isomer may adopt cone and boat conformations [36-38], which interconvert rapidly at room temperature. Studies of the conformational properties of resorcinarenes modified on the lower rim show that the most stable conformer in solution is cone and this trend is favored by bulky substituents in the macrocyclic ring [39].

Continuing with our studies of the structure of polyhydroxylated platforms [12,33,40,41], we found that the bulky aromatic substituents on the lower rim of polyhydroxylated platforms in cone conformation exhibited a dynamic behavior, which stimulated interest in examining the conformational preferences. For this purpose, in this article, the comparative behavior of C-tetra(phenyl)-resorcin[4]arene (1) and C-tetra(phenyl)pyrogallol[4]arene (2) compounds is studied using ${ }^{1} \mathrm{H}-\mathrm{NMR}$ and ${ }^{13} \mathrm{C}-\mathrm{NMR}$ data and dynamic ${ }^{1} \mathrm{H}-\mathrm{NMR}$ spectra.

\section{Results and Discussion}

\subsection{Synthesis and Separation of Conformers}

As mentioned in the introduction, we chose C-tetra(phenyl)-resorcin[4]arene (1) and C-tetra (phenyl)pyrogallol[4]arene (2) in order to explore the dynamic behavior of cone conformers in dimethyl sulfoxide and acetonitrile. In this way, the obtaining of $\mathbf{1}$ and $\mathbf{2}$ was done according to the procedure described in the literature, through the acid-catalized cyclocondensation of benzaldehyde with resorcinol or pyrogallol, respectively [8,9]. The synthesis was carried out through the acid-catalyzed cyclocondensation of phenol with benzaldehyde in ethyl alcohol at reflux condition. In the reaction (Scheme 2), two products were obtained (Supplementary Material, Figures S1 and S10, which were used for dynamic nuclear magnetic resonance (NMR) studies after separation.

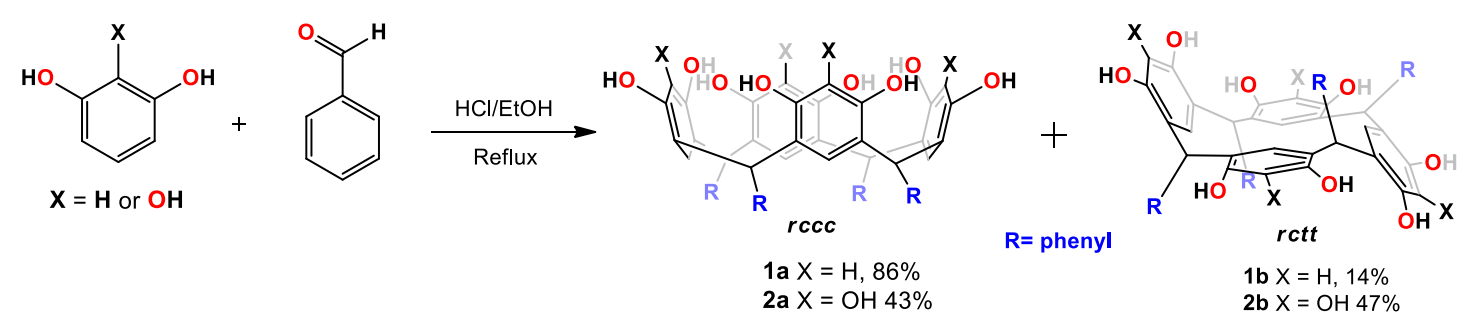

Scheme 2. Synthesis of tetra(phenyl) pyrogallol[4]arene and resocin[4]arene.

In the ${ }^{1} \mathrm{H}$-NMR spectrum of $\mathbf{1 a}$ (Figure S3), individual assignments of the protons were made based on their positions, multiplicities, integral values and comparison of spectral data with reported values of similar compounds [12,40]. In this way, the ${ }^{1} \mathrm{H}-\mathrm{NMR}$ spectrum of $\mathbf{1 a}$ displayed the characteristic signal of a methine bridge at $5.63 \mathrm{ppm}$. In the aromatic region, normally the ortho- and meta-protons of resorcinarene moiety attached to a hydroxyl group produce separate signals and the ortho-protons are shielded by hydroxyl groups, while the meta-protons are unshielded and resonate in the upfield region. Given this, the hydrogen of the tetrasubstituted resorcinol units appears at 6.32 and $6.15 \mathrm{ppm}$, respectively. The signals at 6.97 and 6.75 were attributed to the hydrogen in the aromatic ring of the phenyl substituent on the lower rim. Finally, the signal at $8.53 \mathrm{ppm}$ was assigned to hydroxyl groups in the molecule. As mentioned above, resorcinarenes can exist in conformations of various symmetries; in this way, in the first product formed the ${ }^{1} \mathrm{H}$-NMR showed the characteristic signals for the cone conformation (diastereomer $r c c c$ ). Initially in our case, the signals indicate the existence of highly symmetric cone conformation in solution if the ${ }^{1} \mathrm{H}-\mathrm{NMR}$ spectrum of $1 \mathrm{a}$ is recorded at $333 \mathrm{~K}$ but if the ${ }^{1} \mathrm{H}-\mathrm{NMR}$ spectrum of $\mathbf{1 a}$ is recorded at room temperature, the signals allowed inferring the presence of other conformations, as will be analyzed later. The ${ }^{13} \mathrm{C}-\mathrm{NMR}$ spectrum in DMSO- $d_{6}$ (Figure S4) exhibited nine signals, which agree with the structure of compound 1a, that is, it displayed eight signals for the aromatic systems and the signal at $41.6 \mathrm{ppm}$ confirmed the presence of a methyne-bridge fragment between the aromatic rings, signal assignment was confirmed using the 2D-NMR-HSQC spectrum (Figure S5). 
The second product $\mathbf{1 b}$, obtained in the synthesis, exhibited absorptions for C-O stretching $\left(1159 \mathrm{~cm}^{-1}\right)$, an aromatic ring $\left(1614 \mathrm{~cm}^{-1}\right)$ and the hydroxyl groups $\left(3318 \mathrm{~cm}^{-1}\right)$ in the FT-IR spectrum (Figure S7). The ${ }^{1} \mathrm{H}-\mathrm{NMR}$ spectrum (Figure S8) displayed the characteristic signal of a methine-bridge fragment between the aromatic rings $(5.56 \mathrm{ppm})$ and the aromatic hydrogen of the tetrasubstituted resorcinol unit at 6.12 and $6.22 \mathrm{ppm}$ for the protons in the ortho position and the signal at $6.61 \mathrm{ppm}$ for meta-protons, the signals at 6.84 were attributed to the hydrogen in the aromatic ring of the phenyl substituent on the lower rim. Finally, the signals at 8.57 and $8.46 \mathrm{ppm}$ were assigned to two types of hydroxyl groups in the molecule. The signals observed in ${ }^{13} \mathrm{C}$-NMR spectrum are consistent with the structure (Figure S9).

The reaction of pyrogallol with benzaldehyde was carried out under the same conditions. After $12 \mathrm{~h}$ in reflux, Thin Layer Chromatography (TLC) analysis of the reaction mixture showed two products corresponding to the conformational mixture-cone (2a) and chair (2b) (Figure S11). Then the separation of cone and chair conformers was carried out by using the solvent-extraction technique.

The ${ }^{1} \mathrm{H}-\mathrm{NMR}$ spectrum of product $2 \mathrm{a}$ (Figure S13) exhibited two single peaks, at 7.77 and $7.65 \mathrm{ppm}$, corresponding to two classes of hydroxyl groups, signals corresponding to the pyrogallol residues-the first signal corresponds to a hydroxyl group in position 2 and the second signal for the hydroxyl group in positions 1 and 3. Additionally, all the patterns were consistent with the structure of the expected cone conformer $\mathbf{2} \mathbf{a}$. On the other hand, the spectrum of product $\mathbf{2} \mathbf{b}$ (Figure S17) exhibited four different hydroxyl moieties, at 7.86, 7.67, 7.56 and $7.45 \mathrm{ppm}$, corresponding to two classes of hydroxyl groups attached to pyrogallol residues in the macrocyclic system. Careful analysis of all the patterns confirmed the structure of chair conformer $\mathbf{2 b}$. The increase of signals in the ${ }^{13} \mathrm{C}-\mathrm{NMR}$ spectrum also confirmed the chair conformation (Figure S18). A comparison of the NMR spectra for the two isomer types is shown in Figure 1.

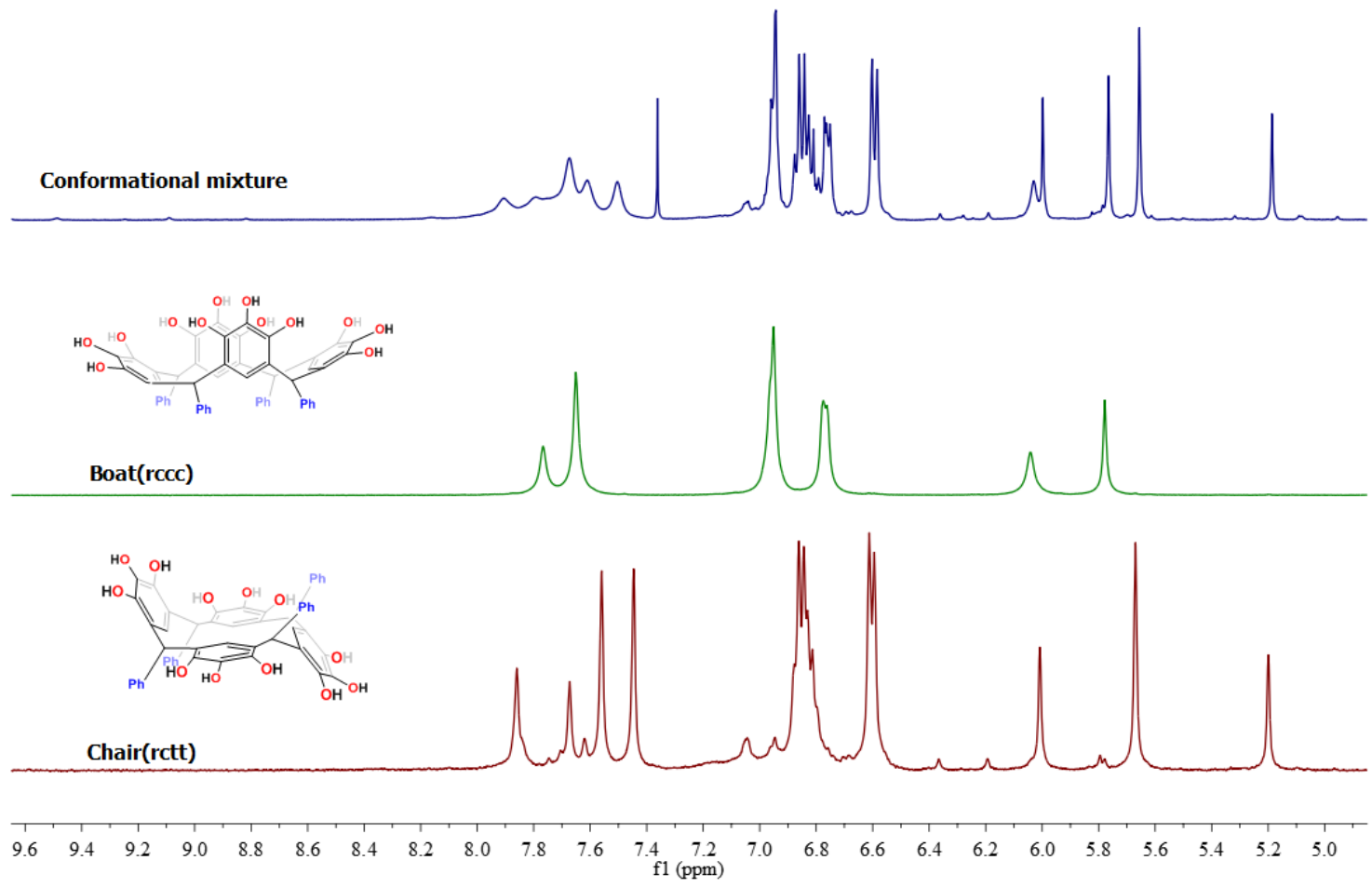

Figure 1. Comparative ${ }^{1} \mathrm{H}-\mathrm{NMR}$ spectra of de products $\mathbf{2} \mathbf{a}$ and $\mathbf{2} \mathbf{b}$ in DMSO- $d_{6}$ at room temperature.

\subsection{Dynamic ${ }^{1} H$-NMR Studies}

As mentioned above, if the ${ }^{1} \mathrm{H}-\mathrm{NMR}$ spectrum in DMSO- $\mathrm{d}_{6}$ of $\mathbf{1 a}$ was recorded at room temperature, the signal in the aromatic region at $6.32 \mathrm{ppm}$ was observed as a broad signal. This fact was interesting, because this behavior is characteristic of a dynamic system in solution. In order to establish this 
behavior in DMSO- $\mathrm{d}_{6}$ initially, the ${ }^{1} \mathrm{H}-\mathrm{NMR}$ spectrum was recorded at a temperature of $333 \mathrm{~K}$ (Figure 1), observing that this signal was better defined, so it was decided to perform a dynamic study at variable temperature. As shown in Figure 2, at the lowest temperature, the spectrum of Compound 1a in the aromatic region (resorcinol residue) exhibited four signals-two for aromatic protons on the upper rim at 6.55 and $6.20 \mathrm{ppm}$ and two signals for the protons on the lower rim at 6.00 and $6.15 \mathrm{ppm}$.

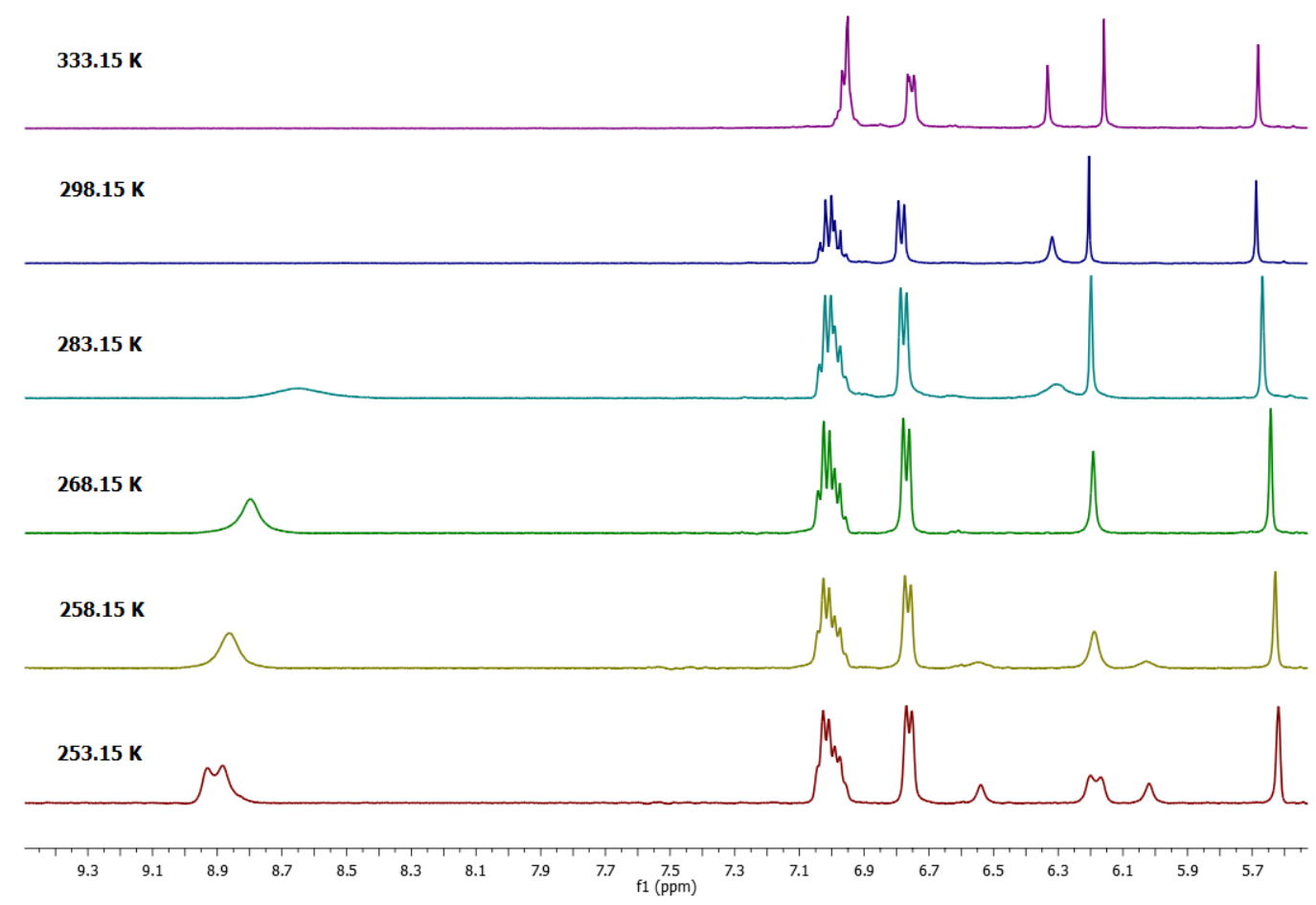

Figure 2. Dynamic study of tetra(phenyl)-resorcin[4]arene (1a) in MeCN-DMSO- $\mathrm{d}_{6}$ mixture.

The ${ }^{1} \mathrm{H}-\mathrm{NMR}$ spectra of conformer $1 \mathrm{a}$ at $253.15 \mathrm{~K}$ was consistent with the presence of two conformers that exhibited two resonances for a flattened ring and two resonances for an opposite ring. This observation prompted a detailed study of the NMR spectra. It has been well established that the conformation of the resorcinarene skeleton can be assigned in solution by a comparison of the chemical shift for the arene resonance in other analogues macrocycles, because the protons in the flattened ring are more shielded. In this way, flattened cone A and flattened cone B (Figure 3) are possible conformations in DMSO- $\mathrm{d}_{6}$ for this macrocyclic system, which is confirmed by other areas of the spectrum, which are consistent with this conformational assignment. In the same way, in DMSO, the spectrum obtained at $268.15 \mathrm{~K}$ shows coalescence of the peaks in the aromatic zone, particularly for resorcinol ring signals, confirming a very dynamic interconversion system between the conformers flattened cone $\mathrm{A}$ and flattened cone $\mathrm{B}$. 


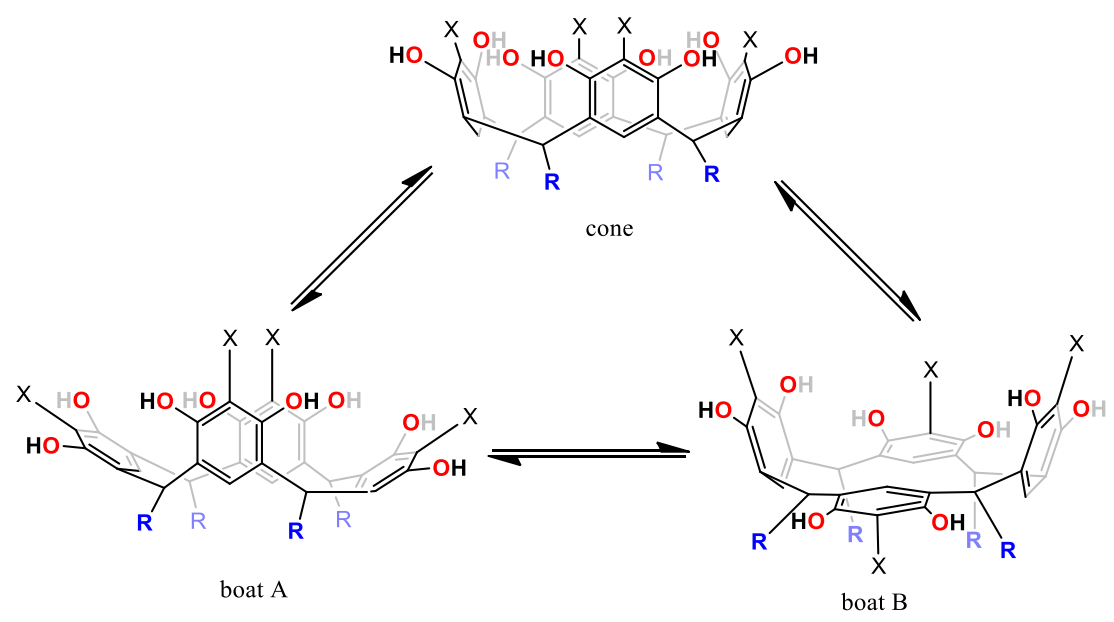

Figure 3. Dynamic behavior of 1a and 2a.

At other temperatures $(283.15,298.15$ and $333.15 \mathrm{~K})$, aromatic protons in ortho- and meta-positions of the resorcinol unit are sensitive to the chemical environment of the different conformations, as has been observed in other similar systems and is favored by the interaction with the solvent. In this way, the ${ }^{1} \mathrm{H}-\mathrm{NMR}$ spectrum of $1 \mathrm{a}$ in DMSO showed mixed conformations, according to the following signals-two protons in the aromatic region (6.32 and $6.15 \mathrm{ppm}$ ) indicate a high degree of conformational equilibrium between cone and flattened cone (A and B) conformers for diastereomer $r c c c$ (Figure 3).

${ }^{1} \mathrm{H}-\mathrm{NMR}$ spectrum of $\mathbf{2 a}$ in DMSO- $\mathrm{d}_{6}$ at $293.15 \mathrm{~K}$ is characteristic of the cone conformation and this change when the temperature decreases (Figure 4). At $248.15 \mathrm{~K}$, the spectrum showed two resonances consistent with the presence of two conformers-flattened cone A and flattened cone B (Figure 3), which showed one resonance at $6.00 \mathrm{ppm}$ for a flattened pentasubstituted pyrogallol unit and one resonance at $6.60 \mathrm{ppm}$ for an opposite pentasubstituted pyrogallol unit and the spectrum obtained at $273.15 \mathrm{~K}$ shows coalescence of these peaks in the aromatic zone. Similarly, and as seen with compound 1a, these observations suggest that the compound exists in two forms in solution, cone and flattened cone conformers. In DMSO- $\mathrm{d}_{6}, \mathbf{1 b}$ showed a similar pattern of signals and this confirms the presence of the two conformers with very small differences with respect to their coalescence temperatures.

According to the known experimental evidence for aliphatic resorcinarenes and pyrogallolarenes, those exhibit a rigid cone $(r c c c)$ structure at room temperature in solution and solid state $[42,43]$ which is established due to the intramolecular hydrogen bonds in the upper rim. In contrast with the behavior of platforms with aliphatic substituent, the experimental evidence for platforms $\mathbf{1 a}$ and $\mathbf{1 b}$ showed that they have a dynamic behavior in solution, this behavior can be due to loss of intramolecular hydrogen bonds on the upper rim, the existence of $\pi-\pi$ interactions of the aromatic system in the lower rim and polar $\cdots \pi, \mathrm{C}-\mathrm{H} \cdots \pi[44,45]$ between solvent molecules and aromatic system permitting a temporal rearrangement of the macrocycle. 


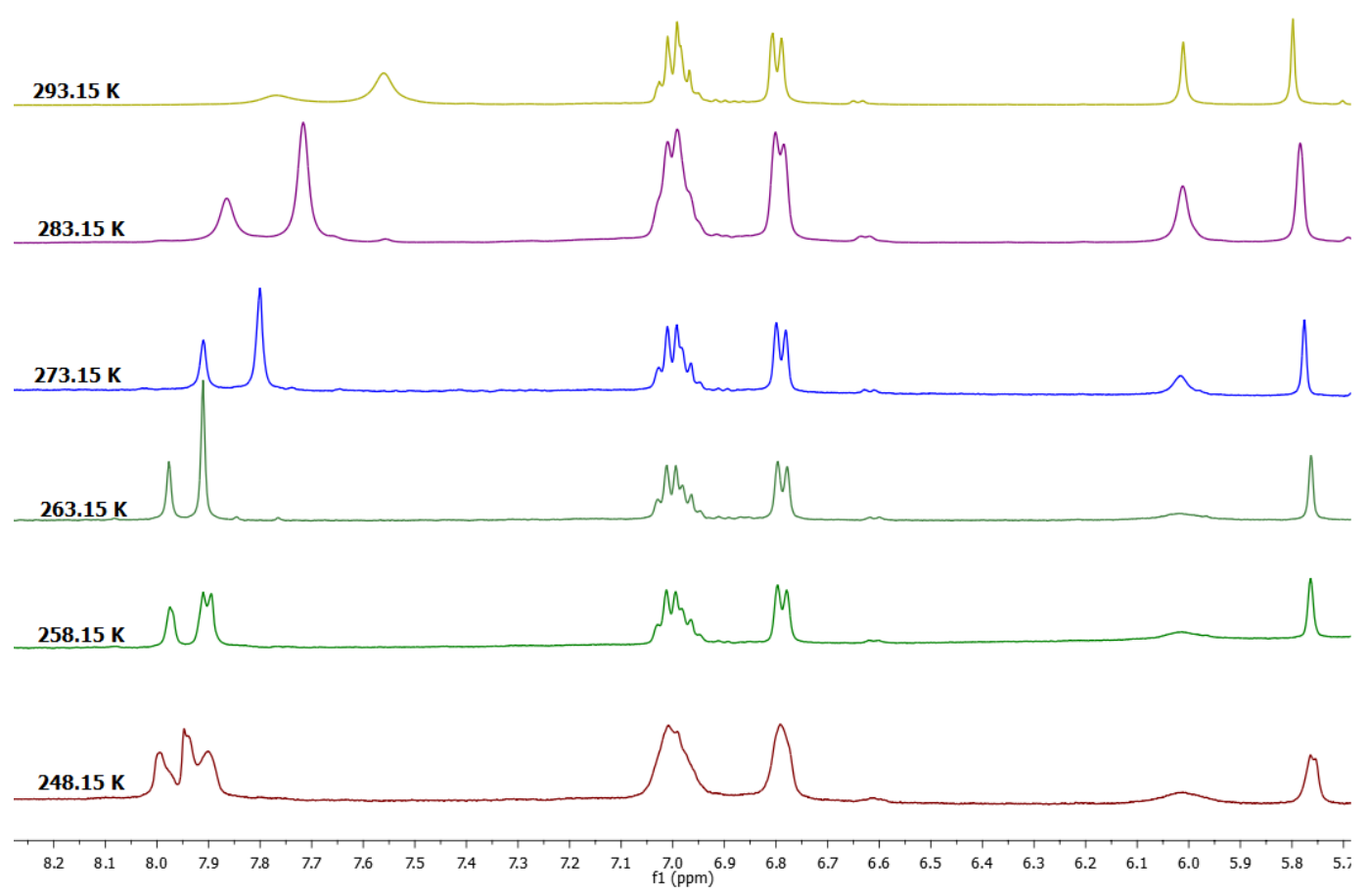

Figure 4. Dynamic study of tetra(phenyl)-pyrogallol[4]arene (2a) in MeCN-DMSO- $\mathrm{d}_{6}$ mixture.

\section{Materials and Methods}

Infrared (IR) spectra were recorded on a ThermoFisher Scientific Nicolet iS10 Fourier transform infrared (FTIR) spectrometer with a monolithic Diamond, Attenuated Total Reflection (ATR) accessory and absorption in $\mathrm{cm}^{-1}$ (Thermo Scientific, Waltham, MA, USA). ${ }^{1} \mathrm{H}$ and ${ }^{13} \mathrm{C}-\mathrm{NMR}$ spectra were recorded at $400 \mathrm{MHz}$ on a Bruker Advance 400 instrument. Molar mass was determined with Agilent 6470 triple quadrupole mass spectrometer. RP-HPLC analyses were performed on a Chomolith ${ }^{\circledR}$ C18 column (Merck, Kenilworth, NJ, USA, $50 \mathrm{~mm}$ ), using an Agilent 1200 Liquid Chromatograph (Agilent, Omaha, NE, USA). Chemical shifts are reported in ppm, using the solvent residual signal. Melting points were measured on a Stuart apparatus (Cole-Parmer, Stafford, UK) and are not corrected. The elemental analysis for carbon and hydrogen was carried out using a Thermo Flash 2000 elemental analyzer (Thermo Scientific, Waltham, MA, USA).

\subsection{Synthesis of Tetra(phenyl)-pyrogallol[4]arene and Resorcin[4]arene}

Synthesis of $C$-tetra(phenyl)-pyrogallol[4]arene. A Pyrogallol solution ( $5 \mathrm{mmol})$ in $10 \mathrm{~mL}$ of ethanol was added dropwise to $0.4 \mathrm{~mL}$ of concentrated chlorine acid (37\%), the mixture was stirred at $0{ }^{\circ} \mathrm{C}$ for $5 \mathrm{~min}$ and then $0.5 \mathrm{~mL}$ of benzaldehyde $(5 \mathrm{mmol})$ was added dropwise. After $10 \mathrm{~min}$, the mixture was heated to $70-80{ }^{\circ} \mathrm{C}$ and refluxed for $12 \mathrm{~h}$ and the solid precipitate was filtered and washed with a mixture of water and ethanol (1:1), producing a pink solid (569 $\mathrm{mg}$ ) at 56\% yield, which was characterized by means IR, ${ }^{1} \mathrm{H}-\mathrm{NMR}$ and ${ }^{13} \mathrm{C}-\mathrm{NMR}$ and used for separation experiments.

Conformation separation. The separation of boat and chair conformers was carried out by using the solvent-extraction technique with mixtures of solvents such as ethyl acetate, water and ethanol. The crude mixture $(200 \mathrm{mg}$ ) was stirred in $10 \mathrm{~mL}$ of a mixture of solvents (ethyl acetate, ethanol and water, at a ratio of 2:1:1, respectively) for $10 \mathrm{~min}$ and the suspended solid was separated by filtration, dried and used for conformational studies, whereupon it was determined to be in the chair conformer configuration. The mixture of solvents was removed by evaporation, resulting in a second red solid that exhibited the boat conformation.

C-tetra(phenyl)pyrogallol[4]arene (boat) m.p. > $350{ }^{\circ} \mathrm{C} \mathrm{IR}\left(\mathrm{ATR} / \mathrm{cm}^{-1}\right)$ : 3300-3600 (broad), 1630, 1500, $1464,1368,1282,1247,1209,1064,1015,163,699,566,416 \mathrm{~cm}^{-1} ;{ }^{1} \mathrm{H}-\mathrm{NMR}\left(400 \mathrm{MHz}, \mathrm{DMSO}-d_{6}\right): \delta 7.77$ 
(s, 4H, OH); 7.65 (s, 8H, OH); 6.95-6.96 (m, 12H, Ar); 6.76-6.77 (m, 8H, Ar); 6.04 (s, 4H, Ar); 5.78 (s, 4H, $\mathrm{CH}) .{ }^{13} \mathrm{C}-\mathrm{NMR}\left(100 \mathrm{MHz}, \mathrm{DMSO}-d_{6}\right): \delta$ (ppm) $145.4 ; 142.0 ; 131.8 ; 128.6 ; 127.0 ; 124.5 ; 121.3$. 41.3. Calcd. For $\mathrm{C}_{52} \mathrm{H}_{40} \mathrm{O}_{12}$ (\%) C 72.89; $\mathrm{H} 4.72 ; \mathrm{O} 22.41$. Found: C 73.85; H 4.67; O 21.49.

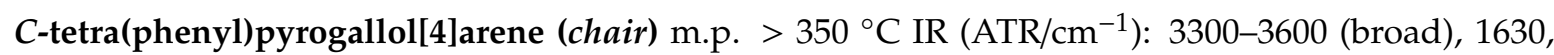
$1500,1464,1368,1282,1247,1209,1064,1015,163,699,566,416 ;{ }^{1} \mathrm{H}-\mathrm{NMR}\left(400 \mathrm{MHz}, \mathrm{DMSO}-\mathrm{d}_{6}\right): \delta 7.86$ (s, 2H, OH); $7.67(\mathrm{~s}, 2 \mathrm{H}, \mathrm{OH}) ; 7.56(\mathrm{~s}, 4 \mathrm{H}, \mathrm{OH}) ; 7.45(\mathrm{~s}, 4 \mathrm{H}, \mathrm{OH}), 6.84(\mathrm{~s}, 12 \mathrm{H}, \mathrm{Ar}) ; 6.60(d, J=8 \mathrm{~Hz}, 8 \mathrm{H}$, $\mathrm{Ar}) ; 6.01$ (s, 2H, Ar); 5.67 (s, 4H, CH); 5.20 (s, 2H, Ar). ${ }^{13} \mathrm{C}-\mathrm{NMR}\left(100 \mathrm{MHz}, \mathrm{DMSO}-d_{6}\right): \delta$ (ppm) 143.8; $141.9 ; 141.6 ; 131.8 ; 131.3 ; 128.7 ; 126.7 ; 124.2 ; 122.4 ; 121.5 ; 121.4 ; 119.8 ; 42.6$. Calcd. For $\mathrm{C}_{52} \mathrm{H}_{40} \mathrm{O}_{12}(\%) \mathrm{C}$ 72.89; H 4.72; O 22.41. Found: C 73.52; H 4.21; O 21.91.

Synthesis of $C$-tetra(phenyl)-resorcin[4]arene. A resorcinol solution $(10 \mathrm{mmol})$ in $20 \mathrm{~mL}$ of ethanol was added to $10 \mathrm{mmol}$ of benzaldehyde, the mixture was stirred at $90{ }^{\circ} \mathrm{C}$ and $2.5 \mathrm{~mL}$ of concentrated hydrochloric acid (37\%) was added dropwise. The solution was refluxed for $6 \mathrm{~h}$ and the precipitated solid was filtered and washed with ethanol, producing a green solid at $86 \%$ yield. The green powder was dried and used for ${ }^{1} \mathrm{H}-\mathrm{NMR}$ analysis. Water was added to the ethanol used in the reaction and washed by inducing the precipitate. The obtained solid was filtered, washed with water and was recrystallized from acetonitrile. The second yellow solid at $14 \%$ yield was dried and used for conformational studies.

C-tetra(phenyl)-resorcin[4]arene(boat) m.p. $>300{ }^{\circ} \mathrm{C} \mathrm{IR}\left(\mathrm{KBr} / \mathrm{cm}^{-1}\right)$ : 3300-3600 (broad), 1600, 1470, $1440,1380,1340,1210,1260,1150,850,740,700 ;{ }^{1} \mathrm{H}-\mathrm{NMR}\left(400 \mathrm{MHz}, \mathrm{DMSO}-d_{6}\right): \delta 8.53$ (s, 8H, OH); 6.98-6.96 (m, 12H, Ar); 6.75-6.74 (m, 8H, Ar); 6.32 (br s, 4H, CH meta to OH); 6.15(s, 4H, CH orto to $\mathrm{OH}) ; 5.63$ (s, $4 \mathrm{H}, \mathrm{CH}) .{ }^{13} \mathrm{C}-\mathrm{NMR}\left(100 \mathrm{MHz}, \mathrm{DMSO}-d_{6}\right) \delta$ (ppm): 152.4; 145.6, 130.7; 128.4; 126.8; 124.3; $120.5 ; 102.2 ; 41.6$.

C-tetra(phenyl)-resorcin[4]arene(chair) m.p. > $\left.300{ }^{\circ} \mathrm{C} \mathrm{IR} \mathrm{(KBr/cm}{ }^{-1}\right)$ : 3300-3600 (broad), 1600, 1470, 1440, 1380, 1340, 1210, 1260, 1150, 850, 740, 700; ${ }^{1} \mathrm{H}-\mathrm{NMR}\left(400 \mathrm{MHz}, \mathrm{DMSO}-\mathrm{d}_{6}\right): \delta 8.52$ (s, 4H, OH); 8.41 (s, 4H, OH); 6,80 (s, 12H, Ar); 6.57 (s, 8H, Ar); 6.31 (s, 4H, Ar); 6.08 (s, 2H, Ar); 5.52 (s, 2H, Ar); 5.49 (s, $4 \mathrm{H}, \mathrm{CH}) .{ }^{13} \mathrm{C}-\mathrm{NMR}\left(100 \mathrm{MHz}, \mathrm{DMSO}-d_{6}\right) \delta$ (ppm): $152.7 ; 152.5 ; 144.7 ; 131.7 ; 129.1 ; 128.9 ; 126.9 ; 124.3$; $121.0 ; 120.6 ; 101.6 ; 42.1$.

\subsection{Dynamic Studies}

The dynamic studies were carried out by using ${ }^{1} \mathrm{H}-\mathrm{NMR}$. The solids $\mathbf{1 a}$ and $\mathbf{2 a}$ were dissolved in a mixture of solvents such as DMSO- $d_{6}$ and acetonitrile (MeCN). The solution was cooled within a range of $296.15 \mathrm{~K}$ to $258.15 \mathrm{~K}$ taking ${ }^{1} \mathrm{H}-\mathrm{NMR}$ spectra each 5 or $10 \mathrm{~K}$.

\section{Conclusions}

C-tetra(phenyl)-resorcin[4]arene and C-tetra(phenyl)-pyrogallol[4]arene were synthesized as conformational mixtures composed of the boat and the chair isomers. The analysis of the conformational mixture showed the formation of cone isomers in a greater proportion for the C-tetra(phenyl)-resorcin[4]arene, while for C-tetra(phenyl)-pyrogallol[4]arene, the chair isomer had the greater proportion. The dynamic studies in the solution phase showed that structures $1 \mathbf{a}$ and $\mathbf{2 a}$ are a dynamic boat in the solution phase, in contrast with previous studies, where the structure was reported as a cone conformer. The dynamic behavior is a consequence of absence of intramolecular hydrogen bonds on the upper rim, as an effect of the aromatic substituent on the lower rim.

Supplementary Materials: The following are available online: Figure S1: ${ }^{1} \mathrm{H}-\mathrm{NMR}$ spectrum DMSO- $d_{6}$ conformational mixture(1a and 1b), Figure S2: IR Spectrum of tetra(phenyl)-resorcin[4]arene(1a), Figure S3: ${ }^{1} \mathrm{H}-\mathrm{NMR}$ spectrum-DMSO- $d_{6}$ of tetra(phenyl)-resorcin[4]arene(1a), Figure S4: ${ }^{13} \mathrm{C}-\mathrm{NMR}$ spectrum- DMSO- $d_{6}$ of tetra(phenyl)-resorcin[4]arene(1a), Figure S5: 2D-NMR-HSQC spectrum-DMSO- $d_{6}$ of tetra(phenyl)-resorcin[4]arene(1a), Figure S6: Dynamic ${ }^{1} \mathrm{H}-\mathrm{NMR}$ study for tetra(phenyl)-resorcin[4]arene(1a), Figure S7: IR Spectrum of tetra(phenyl)-resorcin[4]arene(1b), Figure S8: ${ }^{1} \mathrm{H}-\mathrm{NMR}$ spectrum-DMSO- $d_{6}$ 
of tetra(phenyl)-resorcin[4]arene(1b), Figure S9: ${ }^{13}$ C-NMR spectrum of tetra(phenyl)-resorcin[4]arene (1b), Figure S10: ${ }^{1} \mathrm{H}-\mathrm{NMR}$ spectra of boat $(r c c c)(\mathbf{1 a})$, Figure S11: ${ }^{1} \mathrm{H}-\mathrm{NMR}$ spectrum DMSO- $d_{6}$ conformational mixture(2a and $\mathbf{2 b})$ and chair $(r c t t)(\mathbf{1 b})$, Figure S12: IR Spectrum of tetra(phenyl)-pyrogallol[4]arene(2a), Figure S13: ${ }^{1} \mathrm{H}-\mathrm{NMR}$ spectrum-DMSO- $d_{6}$ of tetra(phenyl)-pyrogallol[4]arene(2a), Figure S14: ${ }^{13} \mathrm{C}-\mathrm{NMR}$ spectrum-DMSO- $d_{6}$ of tetra(phenyl)-pyrogallol[4]arene(2a), Figure S15: Dynamic ${ }^{1} \mathrm{H}-\mathrm{NMR}$ study for tetra(phenyl)-pyrogallol[4]arene(2a), Figure S16: IR Spectrum of tetra(phenyl)-pyrogallol[4]arene(2a), Figure S17: ${ }^{1} \mathrm{H}-\mathrm{NMR}$ spectrum-DMSO- $d_{6}$ of tetra(phenyl)-pyrogallol[4]arene(2b), Figure S18: ${ }^{13} \mathrm{C}-\mathrm{NMR}$ spectrum-DMSO- $d_{6}$ of tetra(phenyl)-pyrogallol[4]arene(2b), Figure S19: ${ }^{1} \mathrm{H}-\mathrm{NMR}$ spectra of conformational mixture, boat $(r c c c)(2 \mathbf{a})$ and chair $(r c t t)(\mathbf{2 b})$ isomers.

Author Contributions: Designed the research, M.M.V.; performed the experiments and collected the data, analyzed the results and corrected and edited the manuscript, M.M.V., J.L.C.-H. and M.Á.V.S. All authors contributed to the preparation of the manuscript and have read and agreed to the published version of the manuscript.

Funding: This research was funded by Department of Science, Technology and Innovation COLCIENCIAS (Colombia). grant conv. 727.

Acknowledgments: We wish to thank the Universidad Nacional de Colombia and José Luis Casas-Hinestroza acknowledge the Administrative Department of Science, Technology and Innovation COLCIENCIAS (Colombia) for his Ph.D. grant conv. 727.

Conflicts of Interest: The authors declare no conflict of interest.

\section{References}

1. Scott, M.; Sherburn, M. Resorcinarenes and Pyrogallolarenes. In Comprehensive Supramolecular Chemistry II; Elsevier: Amsterdam, The Netherlands, 2017; pp. 337-374. [CrossRef]

2. Han, J.; Song, X.; Liu, L.; Yan, C. Synthesis, crystal structure and configuration of acetylated aryl Pyrogallol[4]arenes. J. Incl. Phenom. Macrocycl. Chem. 2007, 59, 257-263. [CrossRef]

3. Yasmin, L.; Coyle, T.; Stubbs, K.A.; Raston, C.L. Stereospecific synthesis of resorcin[4]arenes and pyrogallol[4]arenes in dynamic thin films. Chem. Commun. 2013, 49, 10932. [CrossRef] [PubMed]

4. Pfeiffer, C.; Feaster, K.A.; Dalgarno, S.J.; Atwood, J. Syntheses and characterization of aryl-substituted pyrogallol[4]arenes and resorcin[4]arenes. CrystEngComm 2016, 18, 222-229. [CrossRef]

5. Jain, V.K.; Kanaiya, P.H. Chemistry of calix[4]resorcinarenes. Russ. Chem. Rev. 2011, 80, 75-102. [CrossRef]

6. Patil, R.S.; Zhang, C.; Atwood, J. Process development for separation of conformers from derivatives of resorcin[4]arenes and pyrogallol[4]arenes. Chem. Eur. J. 2016, 22, 15202-15207. [CrossRef]

7. Tunstad, L.M.; Tucker, J.A.; Dalcanale, E.; Weiser, J.; Bryant, J.A.; Sherman, J.C.; Helgeson, R.C.; Knobler, C.B.; Cram, D.J. Host-guest complexation. 48. Octol building blocks for cavitands and carcerands. J. Org. Chem. 1989, 54, 1305-1312. [CrossRef]

8. Hoegberg, A.G.S. Two stereoisomeric macrocyclic resorcinol-acetaldehyde condensation products. J. Org. Chem. 1980, 45, 4498-4500. [CrossRef]

9. Hoegberg, A.G.S. Cyclooligomeric phenol-aldehyde condensation products. 2. Stereoselective synthesis and DNMR study of two 1,8,15,22-tetraphenyl[14]metacyclophan-3,5,10,12,17,19,24,26-octols. J. Am. Chem. Soc. 1980, 102, 6046-6050. [CrossRef]

10. Yan, C.-G.; Chen, W.; Chen, J.; Jiang, T.; Yao, Y. Microwave irradiation assisted synthesis, alkylation reaction and configuration analysis of aryl pyrogallol[4]arenes. Tetrahedron 2007, 63, 9614-9620. [CrossRef]

11. Chen, J.; Chen, W.; Yan, C. Microwave Assisted Efficient Synthesis and Crystal Structures ofO-Hexadecalkylated Pyrogallol[4]arenes. Chin. J. Chem. 2009, 27, 1703-1706. [CrossRef]

12. Casas-Hinestroza, J.L.; Villamil, M.M. Conformational Aspects of the O-acetylation of C-tetra(phenyl)calixpyrogallol[4]arene. Molecules 2018, 23, 1225. [CrossRef] [PubMed]

13. Timmerman, P.; Verboom, W.; Reinhoudt, D.N. Resorcinarenes. Tetrahedron 1996, 52, 2663-2704. [CrossRef]

14. Morales-Morales, D.; Gómez-Benítez, V.; Toscano, R.A. Quasi-Complete Solvation of C-Phenylcalix[4] resorcinarene in the Crystalline State. Single Crystal X-ray Diffraction Study. J. Incl. Phenom. Macrocycl. Chem. 2004, 50, 199-202. [CrossRef]

15. Kumari, H.; Mossine, A.V.; Kline, S.R.; Dennis, C.L.; Fowler, D.A.; Teat, S.J.; Barnes, C.L.; Deakyne, C.A.; Atwood, J. Controlling the Self-Assembly of Metal-Seamed Organic Nanocapsules. Angew. Chem. Int. Ed. 2012, 51, 1452-1454. [CrossRef] 
16. Fowler, D.A.; Mossine, A.V.; Beavers, C.M.; Teat, S.J.; Dalgarno, S.J.; Atwood, J.L. Coordination Polymer Chains of Dimeric Pyrogallol[4]arene Capsules. J. Am. Chem. Soc. 2011, 133, 11069-11071. [CrossRef]

17. Beyeh, N.K.; Valkonen, A.; Rissanen, K. Piperazine Bridged Resorcinarene Cages. Org. Lett. 2010, 12, 1392-1395. [CrossRef]

18. Makeiff, D.; Sherman, J.C. A Six-Bowl Carceplex That Entraps Seven Guest Molecules. J. Am. Chem. Soc. 2005, 127, 12363-12367. [CrossRef]

19. Kazakova, E.K.; Ziganshina, A.Y.; Muslinkina, L.A.; Morozova, J.E.; Makarova, N.A.; Mustafina, A.R.; Habicher, W. The Complexation Properties of the Water-Soluble Tetrasulfonatomethylcalix[4]resorcinarene toward $\alpha$-Aminoacids. J. Incl. Phenom. Macrocycl. Chem. 2002, 43, 65-69. [CrossRef]

20. Waidely, E.; Pumilia, C.; Malagon, A.; Vargas, E.F.; Li, S.; Leblanc, R.M. Host-Guest Complexation of a Pyrogallol[4]arene Derivative at the Air-Water Interface. Langmuir 2015, 31, 1368-1375. [CrossRef]

21. Hong, M.; Zhang, Y.-M.; Liu, Y. Selective Binding Affinity between Quaternary Ammonium Cations and Water-Soluble Calix[4]resorcinarene. J. Org. Chem. 2015, 80, 1849-1855. [CrossRef] [PubMed]

22. Ballester, P.; Biros, S.M. CH- $\pi$ and $\pi-\pi$ Interactions as Contributors to the Guest Binding in Reversible Inclusion and Encapsulation Complexes. In The Importance of Pi-Interactions in Crystal Engineering; John Wiley \& Sons, Ltd.: Chichester, West Sussex, UK, 2012; pp. 79-107.

23. Puttreddy, R.; Beyeh, N.K.; Taimoory, S.M.; Meister, D.; Trant, J.F.; Rissanen, K. Host-guest complexes of conformationally flexible C-hexyl-2-bromoresorcinarene and aromatic N-oxides: Solid-state, solution and computational studies. Beilstein J. Org. Chem. 2018, 14, 1723-1733. [CrossRef] [PubMed]

24. Al'Tshuler, G.N.; Fedyaeva, O.N.; Ostapova, E. The reaction ofC-phenylcalix[4]resorcinarene-based polymer with quaternary ammonium and potassium cations. Russ. Chem. Bull. 2000, 49, 1468-1470. [CrossRef]

25. Kumar, S.; Chawla, S.; Zou, M.C. Calixarenes based materials for gas sensing applications: A review. J. Incl. Phenom. Macrocycl. Chem. 2017, 88, 129-158. [CrossRef]

26. Catti, L.; Tiefenbacher, K.; Pöthig, A. Host-Catalyzed Cyclodehydration-Rearrangement Cascade Reaction of Unsaturated Tertiary Alcohols. Adv. Synth. Catal. 2017, 359, 1331-1338. [CrossRef]

27. Zhang, Q.; Catti, L.; Kaila, V.R.I.; Tiefenbacher, K. To catalyze or not to catalyze: Elucidation of the subtle differences between the hexameric capsules of pyrogallolarene and resorcinarene. Chem. Sci. 2016, 8, 1653-1657. [CrossRef] [PubMed]

28. Eisler, D.J.; Puddephatt, R.J. Structure and Dynamics of Tetrakis(thiophosphinato)resorcinarene Complexes of Silver(I), Gold(I) and Palladium(II). Inorg. Chem. 2006, 45, 7295-7305. [CrossRef]

29. Ngurah, B.I.G.M.; Jumina; Anwar, C. Synthesis and Application of C-Phenylcalix[4]resorcinarene in Adsorption of $\mathrm{Cr}$ (III) and $\mathrm{Pb}(\mathrm{II})$. J. Appl. Chem. Sci. 2016, 3, 289-298. [CrossRef]

30. Al-Trawneh, S.A. Studies on Adsorptive Removal of Some Heavy Metal Ions by Calix[4]Resorcine. Jordan J. Earth Environ. Sci. 2015, 7, 1-9.

31. Li, N.; Harrison, R.G.; Lamb, J.D. Application of resorcinarene derivatives in chemical separations. J. Incl. Phenom. Macrocycl. Chem. 2013, 78, 39-60. [CrossRef]

32. Pietraszkiewicz, O.; Pietraszkiewicz, M. Separation of Pyrimidine Bases on a HPLC Stationary RP-18 Phase Coated with Calix[4]resorcinarene. J. Incl. Phenom. Macrocycl. Chem. 1999, 35, 261-270. [CrossRef]

33. Velásquez-Silva, B.A.; Aguirre, A.A.C.; Rivera-Monroy, Z.J.; Villamil, M.M. Aminomethylated Calix[4]resorcinarenes as Modifying Agents for Glycidyl Methacrylate (GMA) Rigid Copolymers Surface. Polymers 2019, 11, 1147. [CrossRef]

34. Zhang, H.; Dai, R.; Ling, Y.; Wen, Y.; Zhang, S.; Fu, R.; Gu, J. Resorcarene derivative used as a new stationary phase for capillary gas chromatography. J. Chromatogr. A 1997, 787, 161-169. [CrossRef]

35. Thondorf, I.; Brenn, J.; Böhmer, V. Conformational properties of methylene bridged resorcarenes. Tetrahedron 1998, 54, 12823-12828. [CrossRef]

36. Rumboldt, G.; Böhmer, V.; Botta, B.; Paulus, E.F. Rational Synthesis of Resorcarenes with Alternating Substituents at Their Bridging Methine Carbons. J. Org. Chem. 1998, 63, 9618-9619. [CrossRef]

37. Abis, L.; Dalcanale, E.; Du Vosel, A.; Spera, S. Nuclear magnetic resonance elucidation of ring-inversion processes in macrocyclic octaols. J. Chem. Soc. Perkin Trans. 2 1990, 2075-2080. [CrossRef]

38. Konishi, H.; Morikawa, O. Conformational properties of octahydroxy[1.4]metacyclophanes with unsubstituted methylene bridges. J. Chem. Soc. Chem. Commun. 1993, 34-35. [CrossRef] 
39. Knyazeva, I.R.; Sokolova, V.I.; Gruner, M.; Habicher, W.D.; Syakaev, V.V.; Khrizanforova, V.; Gabidullin, B.M.; Gubaidullin, A.T.; Budnikova, Y.; Burilov, A.R.; et al. One-step synthesis of rccc- and rctt-diastereomers of novel calix[4]resorcinols based on a para-thiophosphorylated derivative of benzaldehyde. Tetrahedron Lett. 2013, 54, 3538-3542. [CrossRef]

40. Velásquez-Silva, A.; Cortés, B.; Rivera-Monroy, Z.J.; Pérez-Redondo, A.; Villamil, M.M. Crystal structure and dynamic NMR studies of octaacetyl-tetra(propyl)calix[4]resorcinarene. J. Mol. Struct. 2017, 1137, 380-386. [CrossRef]

41. Aguirre, A.A.C.; Rivera-Monroy, Z.J.; Villamil, M.M. Selective O-Alkylation of the Crown Conformer of Tetra(4-hydroxyphenyl)calix[4]resorcinarene to the Corresponding Tetraalkyl Ether. Molecules 2017, 22, 1660. [CrossRef]

42. Gareth, W.V. CaveCurrent address: School of Biom; Ferrarelli, M.C.; Atwood, J.L.; Cave, G.W.V. Nano-dimensions for the pyrogallol[4]arene cavity. Chem. Commun. 2005, 2787-2789. [CrossRef]

43. Kulikov, O.V.; Negin, S.; Rath, N.P.; Gokel, G.W. Morphologies of branched-chain pyrogallol[4]arenes in the solid state. Supramol. Chem. 2014, 26, 506-516. [CrossRef]

44. Fagnani, D.; Sotuyo, A.; Castellano, R. $\pi-\pi$ Interactions. In Comprehensive Supramolecular Chemistry II; Elsevier BV: Oxford, UK, 2017; Volume 1, pp. 121-148.

45. Mahadevi, A.S.; Sastry, G.N. Cooperativity in Noncovalent Interactions. Chem. Rev. 2016, 116, $2775-2825$. [CrossRef] [PubMed]

Sample Availability: Samples of the compounds $\mathbf{1 a}, \mathbf{2} \mathbf{a}, \mathbf{1} \mathbf{b}$ and $\mathbf{2} \mathbf{b}$ are available from the authors. 